\title{
An Investigation on Effects of Spot Face Geometry on Fatigue Life of Drum Brake's Lever
}

\author{
Barış Y1lmaz, Cihan Kireççi, Bora Güntay, Özgün Yı1maz, Osman Akdağ
}

0000-0003-2439-5636, 0000-0003-0958-7592, 0000-0002-8526-3285, 0000-0002-8526-3285, 0000-0003-3435-5582

${ }^{1}$ Product Development Engineer, Ege Fren Sanayi ve Tic A.S., Izmir/Turkey

\begin{abstract}
Heavy commercial vehicles, which used for construction works, mostly have drum brakes. There are three types of drum brakes named $\mathrm{S}$ cam brakes, $\mathrm{Z}$ cam brakes and Wedge brakes, which are safety related components for operation of the vehicle. Fatigue life of brake components is critical. One of the most important component is lever which transfers actuation force to camshaft. In this study, spot face geometry of the lever was examined. FEA model was prepared using ANSYS software. Two types of specimens were simulated under actuation force of $15 \mathrm{kN}$ by static structural FEM. Results of this three-dimensional stress analysis compared with experimental fatigue life test results to understand the effect of geometrical changes on stress concentration area of the lever. All the experimental results were plotted and assessed by using Weibull Analysis which is one of the widely used lifetime distributions in reliability engineering.
\end{abstract}

Keywords: FEM, Lever, Stress, Deformation, Experiment, Fatigue Life.

\author{
* Corresponding author \\ Cihan Kireççi \\ cihan.kirecci@egefren.com.tr \\ Address: Ege Fren Sanayi ve Ticaret \\ A.S 7405/2 Sokak No: 435060 \\ Pınarbaşı - İzmir \\ Tel: +902323973654 \\ Fax: +902324790208
}

Research paper

$\begin{array}{lr}\text { Manuscript } \\ \text { Received } & 12.12 .2018 \\ \text { Revised } & 21.01 .2019 \\ \text { Accepted } & 06.02 .2019\end{array}$

Doi: 10.30939/ijastech..495925

\section{Introduction and Literature Survey}

In industry of heavy commercial vehicle, especially construction series, high load capacity is critical. One of the important tasks is to stop that high inertia with usage of brake. Maximum number of brakes used in vehicle is eight. Consequently, a large amount of force is applied by air chamber to get needed brake torque. The brake lever transmits actuation force from air chamber to cam shaft. Stress on the lever is directly proportional to this force. Because of that reason, effects of all geometrical features on the lever should be examined by stress analysis. Patel M.V. and Sarawade S.S. (2017) did one such investigation for lever. They presented finite element analysis and topology optimization of a lever. In addition, they studied the material properties of levers as comparison. Equivalent Von-Misses stresses were obtained for both studies. Consequently, they optimized the component by using aluminum alloy and geometrical changes. [5]

Dange et al. (2014) investigated stress pattern of a lever with numerical and analytical methods. They focused on the bending stresses in this analytical solution. Finite ele- ment method was used for fillet radius and optimization. Then, it was observed that failure occurred at maximum bending stress region and numerical and experimental results were very close to each other. In this study, spot face form of the brake lever was studied as several cases by using finite element analysis. Brake lever material was defined as SAE 1050 for that analysis. According to stress analysis, maximum stress distribution and material can affect the fatigue life of lever. [6]

Chen (2012) established results of fatigue testing and theory of plasticity for AISI 1050 Steel. Additionally, he suggested that fatigue life is related with the strain. It was shown that fatigue analysis of this material has good correlation between experimental and analytical results. [1]

Walther (2007) performed fatigue tests with the specimens which was made from SAE 1050 and SAE 1065 materials. He also focused on microstructure of materials, which were exposed to random loading conditions. Amplitude of plastic strain was measured. Number of cycles for the specimens were plotted with respect to strain. [2]

Lee et al. (2005) focused on fatigue theory. It was described that if the number of cycle to failure is between 1 
and 1000 , it is called low-cycle fatigue. If the failure cycle is higher than 1000 , it is called high cycle fatigue. [8]

Fatigue life is also related with stress concentration. Heywood (1947) focused on effects of stress concentration on fatigue life. The stress concentration affects fatigue strength negatively, while the smaller size of stress concentration helps the increase fatigue life. [3]

\section{Problem Definition}

Most brake component failures occur due to loads exceeding the component's stress limit. Material selection and geometrical design have a key role to prevent any early failure. In this study, material of the lever is SAE 1050. Critical geometries of the lever are splines and spot faces, which are shown in Figure 2.1. The crack started from spline tooth to spot face at the cycle 29278. It is an unacceptable situation for safety components of the vehicle. The objective of this study is to investigate the effect of spot face form on fatigue life and failure mode.

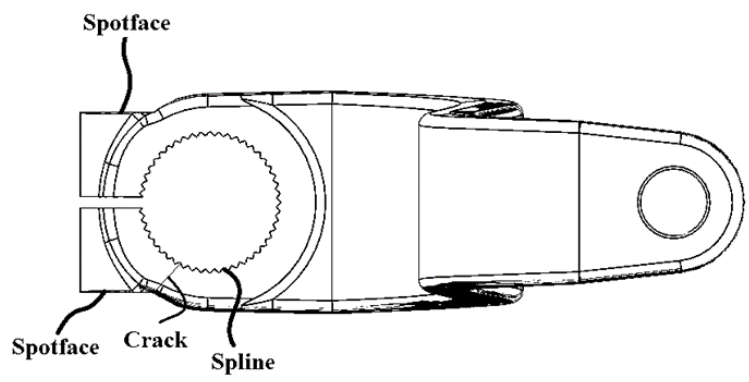

Fig 2.1 Drum Brake Lever

\section{Finite Element Model and Results}

In this study, ANSYS Workbench environment was used for the finite element analysis. FEM is based on formula between force, stiffness and displacement matrices. Formula of multi-degree of freedom static system is given in the Equation 3.1 and stiffness matrices are consisted with no simplification. All components related with the lever were modelled in 3D to reflect real boundary conditions. They were SOLID186 and SOLID187. Furthermore, CONTA174 and TARGE170 were used as a contact element.

$$
[\mathrm{K}] \times\{\mathrm{X}\}=\{\mathrm{F}\}
$$

In the finite element model, material models were defined as multilinear elastic and plastic strain - stress values for the bracket and lever to simulate plastic deformation on the components.

Stress vs. Plastic strain curve of the bracket material is shown in Figure 3.1.

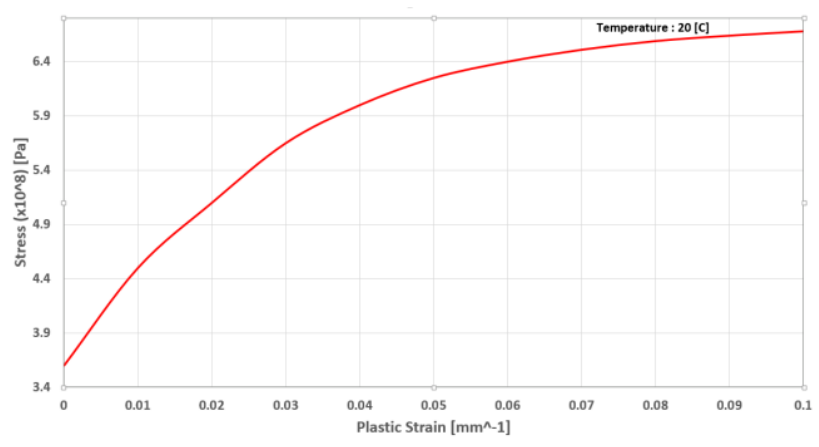

Fig 3.1(a) Stress vs. Plastic strain curve of GGG50

Stress vs. Plastic strain curve of the bracket material is shown in Figure 3.1

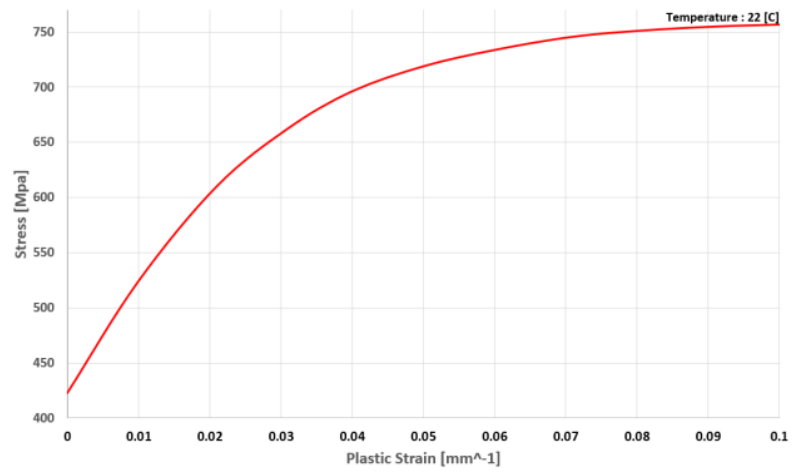

Fig 3.1(b) Stress vs. Plastic strain curve of SAE1050

Geometrical model is shown in Figure 3.3. Materials of parts is given in table 3.1 .

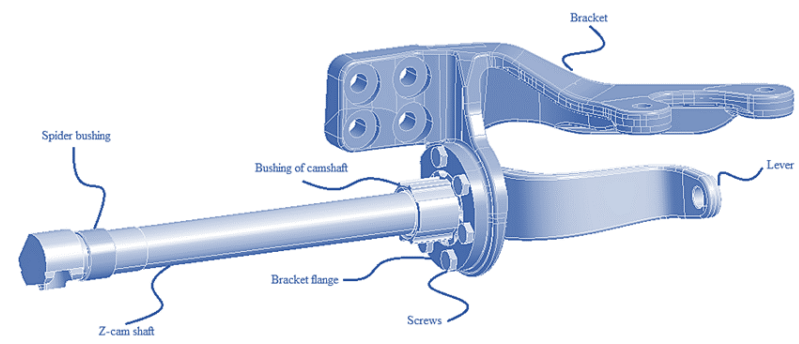

Figure 3.3 Finite element model geometry

For this system, boundary conditions were applied for the condition in which shoes contacted with the drum. The $\mathrm{x}-$ axis was coincident with shaft axis and $y$-axis was perpendicular to the upper surface of bracket. In addition, z-axis was perpendicular to axle mounting surfaces on bracket. 


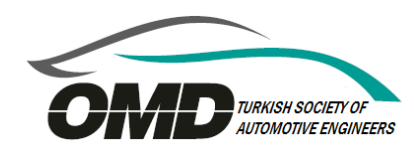

Table Hata! Belgede $\begin{gathered}\text { belirtilen } \\
\text { rastlanmadı..1. Materials of parts }\end{gathered}$
\begin{tabular}{|c|c|}
\hline Part Description & Material \\
& GGG 50 \\
\hline Bracket & SAE 8620 \\
\hline Cam Shaft & ST 37 \\
\hline Bracket Flange & SAE 1050 \\
\hline Lever & Bronze \\
\hline Spider Bushing & Hostaform C 9021 \\
\hline Cam shaft Bushing & Structural Steel \\
\hline Screws &
\end{tabular}

Cam side of the shaft was fixed at UX, UY, UZ, RX, RY and RZ. Bracket was fixed on mounting surface, which has four holes.

Frictional contact conditions were defined between all components, which were in contact with each other except thread portions of screws. Bonded contacts were defined between thread portions of screws and related components. Bracket flange mounting screws were designed with minor thread diameter and $40 \mathrm{kN}$ bolt pretension was defined for each.

Force was applied on the hole surface of lever on y-axis and its magnitude was $15 \mathrm{kN}$. Additionally, reaction forces were applied on air chamber mounting surfaces of bracket. The screw which fix lever to z-cam shaft was defined with bolt pretension of $42 \mathrm{kN}$.

There were two types of levers in this study. One of them was named as LD14R0, which has $14 \mathrm{~mm}$ spot face with no radius, while, the other was named LD14R2, which has $14 \mathrm{~mm}$ spot face with $2 \mathrm{~mm}$ radius.

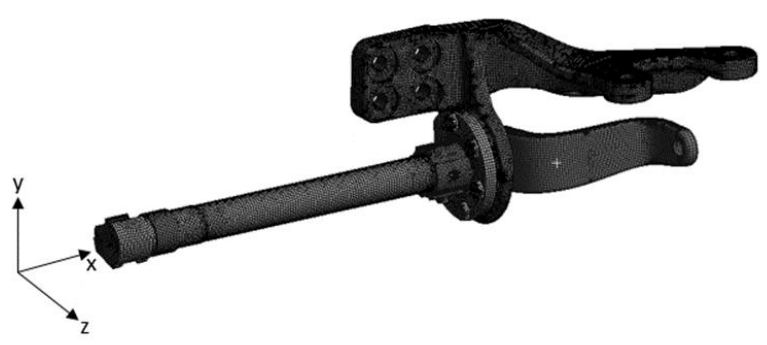

Figure 3.4 Mesh model of the system

According to the FEA results, the maximum principal stress of lever was found on splines. Maximum normal stress and maximum principal stress values are shown in Table 3.2.

\begin{tabular}{|r|c|c|}
\hline Lever Name & LD14R0 & LD14R2 \\
\hline Maximum Normal Stress [MPa] & 538.1 & 438.1 \\
\hline Maximum Principal Stress [MPa] & 682.92 & 498.49 \\
\hline
\end{tabular}

Table Hata! Belgede belirtilen stilde metne rastlanmadı..2. Maximum stress values of components

Results for LD14R0 is shown in Figure 3.5 and Figure 3.6.

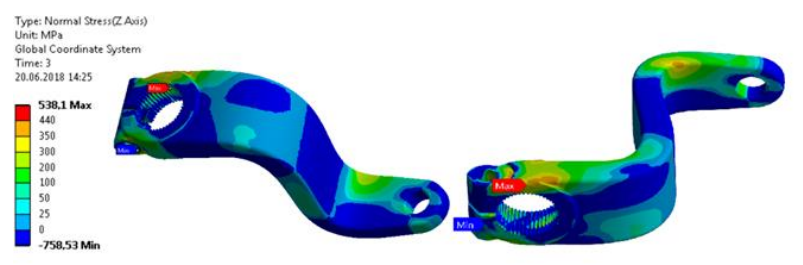

Figure 3.5 Normal stress plot for LD14R0

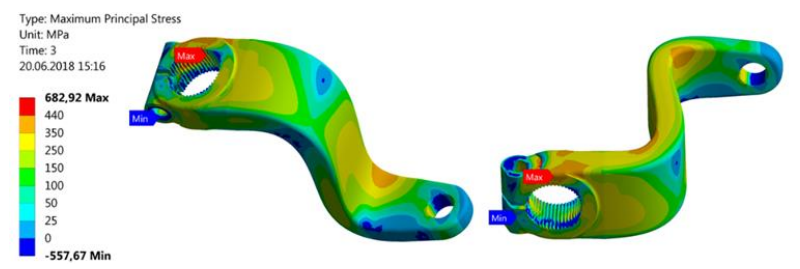

Figure 3.6 Maximum principal stress plot for LD14R0

Results for LD14R2 is shown in Figure 3.7 and Figure 3.8.

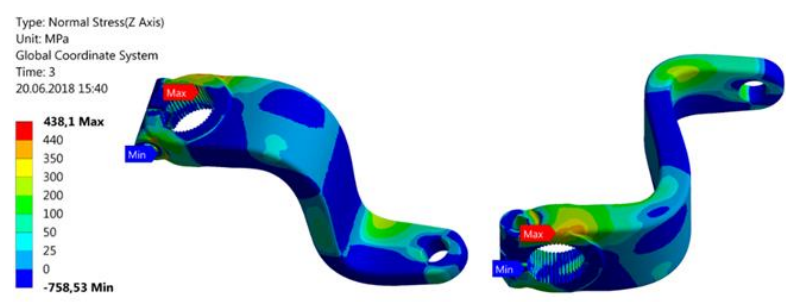

Figure 3.7 Normal stress plot for LD14R2

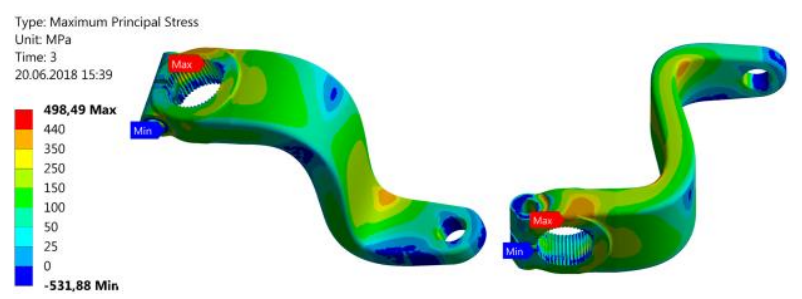

Figure 3.8 Maximum principal stress plot for LD14R2

\section{Test Setup and Results}

An experimental setup, which is shown in Figure 4.1, was designed to simulate real loading conditions on the vehicle. Test load was applied to lever in one way as $15 \mathrm{kN}$ for 2 seconds each cycle by a T30 air chamber. 
Two types of specimens were used for tests. One of them is LD14R0 which has $\varnothing 14 \mathrm{~mm}$ spot diameter with no edge radius and the other one is LD14R2 which has $\varnothing 14 \mathrm{~mm}$ spot diameter with $\mathrm{R} 2 \mathrm{~mm}$ edge radius. Each test was repeated for five specimens under same loading conditions.
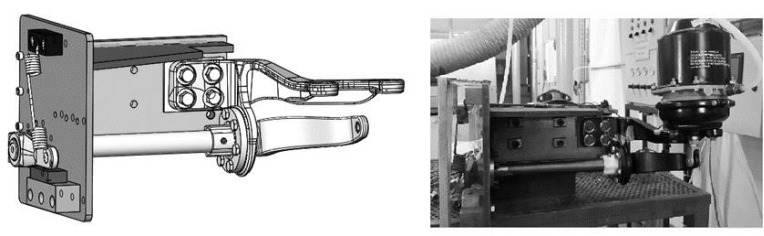

Figure 4.1. Test setup for lever

Additionally, tripwire was used on lever and bracket to stop the system when failure occurred.

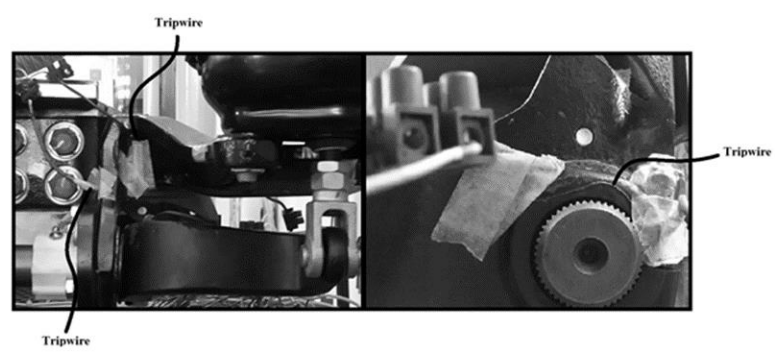

Figure 4.2. Test setup for lever

Results are shown in Table 4.2.

Table Hata! Belgede belirtilen stilde metne rastlanmadı..2. Test Results

\begin{tabular}{|c|c|c|c|}
\hline $\begin{array}{c}\text { Reference } \\
\text { Lever No }\end{array}$ & Cycle & $\begin{array}{c}\text { Modified } \\
\text { Lever No }\end{array}$ & Cycle \\
\hline 1 & 29278 & 1 & 111180 \\
\hline 2 & 64359 & 2 & 148554 \\
\hline 3 & 36481 & 3 & 137264 \\
\hline 4 & 80118 & 4 & 131344 \\
\hline 5 & 41643 & 5 & 167308 \\
\hline
\end{tabular}

It was calculated according to the worst case by using the Weibull analysis with $95 \%$ accuracy that $90 \%$ of the reference levers would exceed 12960 braking cycles, while, $90 \%$ of the modified levers would exceed 88263 braking cycles.

Weibull distribution plot, which was calculated from the test results, is shown Figure 4.4.

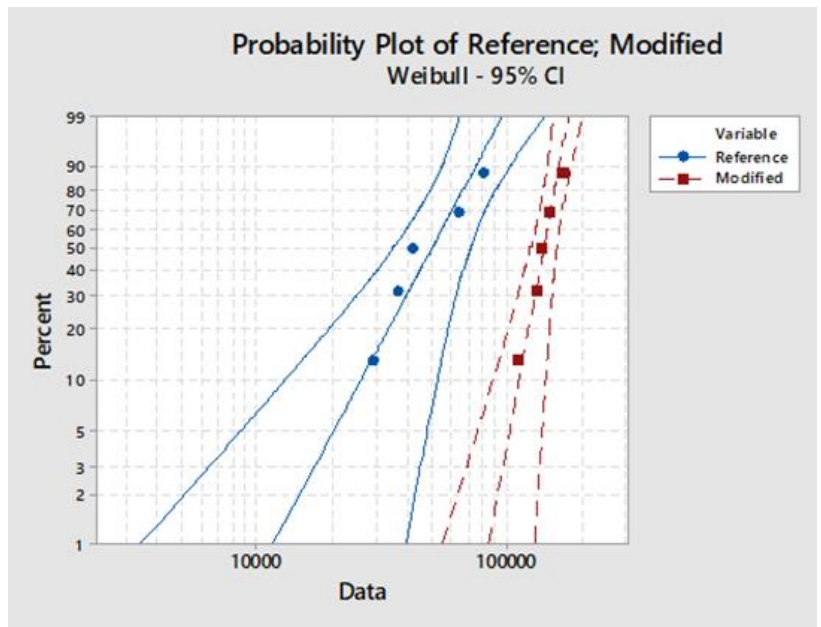

Figure 4.4. Weibull distribution plot

\section{Conclusions}

In this study, critical geometry features of brake lever were analyzed by FEA and positive effect of small geometrical changes on fatigue life was determined. Then results were correlated with the real constraints with worst case scenario of load condition.

In the experimental tests, there were variations seen on fatigue life cycle of specimens due to the manufacturing tolerances. These variations show that the notch effect can vary from part to part.

It was observed that decreasing the notch effect with spot face radius increases the fatigue life of part significantly. And it was also detected that variability of specimens fatigue life cycle was reduced with decreasing the notch effect logarithmically. But in assembly, size of bolt and nut which are used to mate cam-shaft and lever, limits increasing spot face radius.

According to the results of the study, approximately $18 \%$ reduction in maximum stress values, which obtained in the FEA, increased the fatigue life cycle of specimens approximately $500 \%$ by adding $\mathrm{R} 2$ radius on edge of spot face.

These results show that minor changes in geometry features on critical stress region of the part, which is obtained as a result of manufacturing process, has a significant effect on the fatigue life, as a result of stress concentration reduction on critical sections.

As a future study, strength optimization and weight reduction options can be assessed.

\section{References}

[1] Chen, W.-R. (2012). Experimental and Analytical Fatigue Analysis on AISI 1050 Steel. 45-62. Taipei, 55 Hwa Kang Rd., Taiwan.

[2] F. Walther, D. E. (2007). Fatigue life calculation of SAE 
1050 and SAE 1065 steel under random loading. International Journal of Fatigue 29, 1885-1892.

[3] Heywood, B. R. (1947). The Relationship between Fatigue and Stress Concentration. A.M.I.Mech.E, 81.

[4] K. Dems, W. G. (1998). 2D shape optimization with static and dynamic constraints. Structural and Multidisciplinary Optimization, 201-207.

[5] M. V. Patel, S. S. (2017). Design and Weight Optimization of Parking Brake Lever. ICETEMR-17, 367-374.

[6] Mr. M. M. Dange, P. S. (2014). Stress Analysis of Bell Crank Lever. IJRITCC, 2423-2430.

[7] Sonmez, F. O. (2007). Shape optimization of 2D structures using simulated annealing. ELSEVIER, 3279-3299.

[8] Yung-Li LEE, Jwo PAN, Richard B. HATHAWAY, Mark E. BARKEY. (2005). Fatigue Testing and Analysis. Burlington: Elsevier Inc. 